\title{
Tourism and mobile devices: provenance of academic research through a bibliometric study
}

\author{
Francisco José Ortega-Fraile, Miguel Ángel Ríos-Martín and \\ Cristina Ceballos-Hernandez \\ Department of Financial Economics and Operations Management, \\ University of Seville, Seville, Spain
}

Tourism and mobile devices

\begin{abstract}
Purpose - This paper aims to outline a map of all the research that exists on mobile technology and tourism archived in the two main databases worldwide (Web of Science and Scopus). Accordingly, with the identification of all the scientific articles that deal with both mobile technology and tourism, the authors seek to ascertain the evolution of mobile technology in the tourism sector through the years, countries, universities and authors and determine the various collaborations brought about between authors, universities, institutions and/or companies in various research projects. Finally, it also allows the authors to distinguish the main topics under study within the scope of 'mobile tourism'.

Design/methodology/approach - A mixed methodology has been carried out. The search focused on the principal databases of bibliographic references and citations of periodical publications, such as articles from scientific journals, books and other types of printed material. Once the results were obtained in the respective databases, it was necessary to be able to work with them. In this respect, the authors had to extract the relevant data and dump it in a bibliographic reference manager, for which they chose Mendeley. After this, the tabulation of data was performed in Excel and tables and graphs were created from all the data collected.

Findings - The main results obtained and analyzed are the number of articles per year, countries and universities. In the same way, it is interesting to highlight the number of countries and universities that participate in each article under study. On the other hand, an analysis has been carried out regarding the number of articles per author, as well as the topics dealt with in the different articles.

Originality/value - This analysis reveals the role that has been played by mobile phones in tourism since the first scientific article was recorded in 2002. In this regard, in recent years there has been a significant increase in the number of articles, finally resulting in moderate figures in relation to countries (40) and universities (233) that have formed part of the subject matter under study. In contrast to other areas of research in tourism, the relevance of this subject is therefore evident, as is the need for greater background knowledge to establish research models adapted to the new reality of tourism in a world of ever-increasing mobility.
\end{abstract}

Keywords Hotel, Tourism, Smartphone, Application, Mobile device

Paper type Research paper

(C) Francisco José Ortega-Fraile, Miguel Ángel Ríos-Martín and Cristina Ceballos-Hernéndez. Published in Journal of Tourism Analysis: Revista de Análisis Turistico. Published by Emerald Publishing Limited. This article is published under the Creative Commons Attribution (CC BY 4.0) licence. Anyone may reproduce, distribute, translate and create derivative works of this article (for both commercial and non-commercial purposes), subject to full attribution to the original publication and authors. The full terms of this licence may be seen at http://creativecommons.org/licences/by/4.0/legalcode

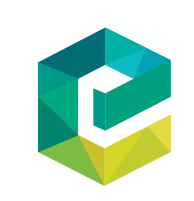

Journal of Tourism Analysis: Revista de Análisis Turístico Vol. 25 No. 1, 2018 pp. $91-112$ pp. 91-112
Emerald Publishing Limited
$2254-0644$ DOI 10.1108/JTA-02-2018-0008 
JTA

25,1

92

\section{Introduction}

In a world in which mobile technology has evolved from being an extra complement in our lives to constituting an essential need, to such an extent that, in developed societies, this technology could be included within the first ranks of the Maslow pyramid, our interest arises in ascertaining the link that this technology has with tourism. In this respect, the research presented here aims to show what can be found together in the scientific literature on mobile technology and tourism.

First, reference has to be made as to how information technologies in tourism have grown in recent years as never before, which helps to gather client demands in a timely manner (Singh and Kasavana, 2005; Connolly and Lee, 2006; Law et al., 2009). In this respect, Law et al. (2009) indicate that ubiquity (characteristic of new information technologies, and of mobile devices in particular) helps towards providing a quality service, and therefore improves operational efficiency and costs. In addition, Law et al. (2009) state that the adoption of new information technologies in the tourism and hotel industry helps companies manage information proactively, while also positively influencing the way in which investments and decisions are made. Thus, today's fast-paced world makes information technology an essential element in tourism for the management of competency and marketing of these companies, regardless of their size.

Within this sea of technology, information and tourism, many tourists use a smartphone or other mobile device to book a hotel, buy a flight, consult information about a location, check the weather, search for opinions on accommodation, inquire about different activities or attractions in a city and consult the different transport options to move from one place to another, and innumerable other actions that can be carried out by means of a mobile device (No and Kim, 2013; Kim and Law, 2015). In this way, the tourist of the twenty-first century is an interconnected tourist, in such a way that the whole process of the trip is recorded in the network as if it were a logbook. The internet is thus present before, during and after the trip, as mobile technology enables tourists to share their experience at any time and place (Tussyadiah, 2013).

Therefore, the growing importance of smartphones and mobile technology in tourism has made mobile communication an essential channel for companies in the sector. In this regard, it is observed that companies have increasingly paid special attention in the provision of mobile services to travelers (Stienmetz et al., 2013; Kim and Law, 2015), as this technology breaks through two important barriers, those of time and geographical location, in such a way that the tourist product or service is constantly available anywhere (Grant and O'Donohoe, 2007).

However, new information technologies suppose a benefit for not only tourism but also the customers and suppliers. Clients can search for and buy the tourist product according to the requirements that they deem appropriate (an example of this is given in the multiple mobile applications available and the various possibilities of narrowing the selection therein). On the other hand, the provider of the tourist product or service can manage and distribute without any geographical limit, thereby contributing toward the globalization and extension of its industry (Buhalis and Law, 2008; Ip et al., 2011). In the same way, the current trend that is better known as the study of "big data", whereby greater and more continuous access to what the client demands is available through the new information technologies, helps to customize and personalize the tourism product (Niininen et al., 2007; Law et al., 2009).

However, in contrast to that stated above, Law et al. (2007) and Ip et al. (2011) indicate that, given the characteristics of the hotel sector as being a customer-oriented and serviceoriented sector, it is inevitable that this industry will find it hard to appreciate the benefits and potential of new information technologies, as is often the case with small- and mediumsized companies. In this respect, Camacho-Mateos et al. (2015), show how a hotel in the city 
of Seville acquires first place in the Trip Advisor ranking with a practically null Web 2.0 policy, stating that "its success lies in the off-line treatment with the public, in its ability to connect with customers and know their tastes to satisfy them to the fullest". However, Fuchs et al. (2014) tell us that this reality is changing, as hoteliers themselves are immersed in the new concept of "big data", whereby technology, specifically in the form of mobile devices, is becoming a major ally for obtaining diverse information on customers. In this respect, $\mathrm{Ni}$ et al. (2016) and Fuchs et al. (2014) explain how the value of an organization is limited to the amount of information it possesses. Highly interesting information can be obtained through mobile devices mobile devices and different applications to define the commercial line of the company: information such as preferences and tastes of customers, geolocation, displacements and frequency of visits to an establishment or place.

Faced with this new scenario, many managers in the tourism sector possess inadequate knowledge regarding the new information technologies, and hence must familiarize themselves with the advantages that these tools have to offer, and must dedicate both time and effort to improving their management. In this way, managers of the tourism industry should maintain good relations with customers by using the appropriate information technologies, integrating these into the company and also by teaching and motivating employees to master these tools, at the same time as keeping up-to-date with respect to the latest technological trends (Ip et al., 2011; Law et al., 2009).

With this panorama of mobile technology in the tourism industry, we are faced with the question of how much effort has been invested in the scientific field on this subject. According to Kim and Law (2015), previous studies have shown the importance that bibliographic reviews hold in the identification of the state of research of a specific topic, that is, what has been studied, what is currently being studied and what deserves further study. The objective of our work is therefore to determine exactly what is written about mobile technology and tourism in the two main scientific databases: Web of Science and Scopus. In this respect, the work presented here helps to identify the evolution of tourism and mobile technology in scientific research, by establishing a list of those countries that are at the forefront of a topic, while helping those researchers interested in mobile technology and tourism to identify which authors, universities, institutions and companies are leaders in "mobile tourism". Likewise, a review of the most popular topic dealt with in the articles studied is also given.

We can conclude this section by expressing the need to carry out quantitative studies on the state of this topic in certain fields of research, as this will help us determine the research needs of a specific sector (Phillips and Moutinho, 2014; Ruhanen et al., 2015).

\section{Objective}

This research aims to outline a map of all the research that exists on mobile technology and tourism archived in the two main databases worldwide (Web of Science and Scopus).

Accordingly, with the identification of all the scientific articles that deal with both mobile technology and tourism, we seek to ascertain the evolution of mobile technology in the tourism sector through the years, countries, universities and authors, as well as to determine the various collaborations brought about between authors, universities, institutions and/or companies in various research projects. Finally, it also allows us to distinguish the main topics under study within the scope of "mobile tourism".

\section{Status of the issue}

Tourism has always been a sector at the forefront of research and has assumed changes produced in society ahead of other sectors. However, it was not until 1970 that interest in 
JTA

25,1

94

research in tourism was raised as an economic, social and cultural phenomenon (Airey, 1979; Graburn and Jafari, 1991; van Doren et al., 1994; Echtner and Jamal, 1997; Cheng et al., 2011). In the study by Cheng et al. (2011) on the development experienced by tourist journals, they point out that more than half of these journals have debuted in the last decade, and more scientific journals have appeared every year. In this regard, Weiner (2001) suggests that the constant requirement of publication by the faculties constitutes a key factor in the proliferation of scientific journals.

On the other hand, we have recently witnessed a change in the paradigm of the business of tourism, which has been largely motivated by new technologies; thereby transforming the nature of tourism, the hotel sector, processes, companies and that of competency itself (Porter, 2001; Law and Jogaratnam, 2005; Grant and O'Donohoe, 2007; Buhalis and Law, 2008; Law et al., 2009; Ip et al., 2011; Kim and Law, 2015).

Given the circumstances described, it is inevitable that such a reality has its reflection in the scientific literature, whereby a large number of publications have been generated that deal with technology and tourism, as stated by Cheng et al. (2011). Proof of this is given in several bibliographic reviews, such as the one carried out by Law et al. (2013) on the progress and development of information technologies in the hotel sector, and that by Zeng and Gerritsen (2014), which carries out a study on everything that has been written in relation to social networks and tourism. However, according to Law et al. (2009) and Ip et al. (2011), very few reviews analyze the publications on new technologies and tourism, or on the progress of these technologies in the tourist sector; moreover, these reviews are limited, as they are reduced to only a few specific journals. This lack of research is also endorsed by other authors such as Yoo et al. (2011) and Oh et al. (2004). It should therefore be noted that, despite the efforts of certain authors, according to Law et al. (2009), there is no standardized list of journals that publish on information technologies in tourism.

Another aspect that deserves special attention when discussing new technologies and tourism is that of obsolescence: in certain cases, existing bibliographical reviews have become obsolete because of the rapidity with which the technological world changes.

On the other hand, although there are only a few revisions of the literature on new technologies and tourism, still fewer publications exist that analyze mobile technology and tourism. This circumstance is made manifest, as only one review can be found that addresses this topic. Said publication is that of the authors Kim and Law (2015), which analyzes 104 articles published between 2000 and 2013 on smartphones in tourism and hotel marketing. This review remains in the qualitative field however, since it analyzes the smartphone from the perspective of the employer and the consumer, without considering the relationships that these articles could have with the countries, universities and magazines where they are published. In fact, Kim and Law (2015) themselves indicate that, despite the growing importance of smartphones, there is a clear lack of bibliographic reviews on the use of the smartphone in the context of tourism and hotel marketing. In this respect, our study is committed to go a little further and extend the bibliometric analysis to articles that deal with tourism and any type of mobile device.

Scientific journals symbolize the development of a field of research: not only are they the showcase of new research but also they constitute a stage on which all the progress and trends of a scientific area can be observed (Cheng et al., 2011; Ip et al., 2011; Leung and Law, 2005). In this respect, the tourism sector has paid special attention in recent years to the development of its scientific journals, as stated by Cheng et al. (2011), who explain that a complete idea of the structure of the tourism sector can be obtained through academic journals. This is a field that has been studied by a large number of disciplines throughout history, in which Jafari and Ritchie (1981) identified five major areas of knowledge in the study of tourism, such as 
economics, sociology, psychology, geography and anthropology, which were increasing over the years because of the multidisciplinary nature of the tourism sector until, in 2011, Cheng et al. (2011) identified up to 29 different disciplines that study tourism in their various journals, and hence there is now a greater specialization in scientific journals on tourism, with the consequent increase in their number. This proliferation of disciplines that study tourism is nothing more than a symbol of the progress that this sector has experienced.

The tourist companies' own structure helps to define what has and has not been investigated on an issue. Thus, Ip et al. (2011), on analyzing the progress of information and communication technologies in the hotel sector through publications made between 1998 and 2008, establish seven dimensions that match the departments of a hotel: human resources and practices, security, reservations, revenue management, marketing, customer service and strategic and operations management.

Cheng et al. (2011) risk a little more and link all of the above with the variation of journal titles and their mission over the years. These authors emphasize that this evolution helps researchers understand how the tourism sector has progressed and how each discipline has been involved in this process. In this way, it has been observed how the titles of these journals have evolved from being general to more specific.

In short, it can be said that the improvement of academic journals reflects the development and progress of a scientific community (Graburn and Jafari, 1991; McKercher, 2005; Cheng et al., 2011). Along these lines, according to Sheldon (1990) and Cheng et al. (2011), a mature research field has its own journals with diverse sub-areas of knowledge, where the ideas of a specific group of researchers are revealed, who share the same values, experience and/or interests in a subject or discipline, as Burdge (1983) indicates.

On the other hand, bibliographic reviews lead to the systematization and classification of journals on a specific subject. Thus, as Korobkin (1999) and Jamal et al. (2008) establish, the rankings on tourist journals provide an incentive for the editors of journals to select certain work, but these wishes of the editors regarding the selection of certain articles can also encourage the authors to publish in their journals, thereby producing research along the same lines.

Given that this work focuses on the analysis of articles published on mobile technology and tourism from 1983 to 2015, it must be stated that although scientific papers are not the only means by which knowledge and new research is disseminated, they do gather a series of characteristics that render them indispensable in the investigation of our times. Hence, Weiner (2001) defines three principal functions of scientific journals:

(1) produce, disseminate and exchange academic knowledge;

(2) provide the means to evaluate research and academic work to distribute research funds; and

(3) report decisions that involve agreements and promotions.

Similarly, another reason that places scientific papers as the focus of our study is that these serve as a distribution channel of knowledge that can deliver results and rigorous and impartial points of view on the matter that concerns us, as expressed by Ip et al. (2011).

Finally, it should be borne in mind that the trends in hotel marketing research journals have evolved as the reality of the hotel industry has required. Accordingly, while consumer behavior is a topic that has been addressed more consistently by tourism research over the years, issues such as social responsibility and sustainability have only recently featured in current research. However, researchers' efforts to address clients' emotions, perceptions and new forms of relationships through social networks remain insufficient and should be investigated profusely (Yoo et al., 2011). 
JTA

25,1

96

\section{Methodology}

The proliferation of scientific and commercial articles on the subject under study has become highly evident in recent years, probably motivated by the information society in which we live and the need for communication. In this respect, and to choose the information that is indeed relevant to our analysis, a list of quality and convenience criteria were defined to select and analyze those scientific articles that will effectively address both tourism and mobile devices.

It should be qualified that, as Domingo Carrillo et al. (2014) point out, by following the line of other bibliometric studies, we have focused on the analysis of papers published in journals, in such a way that books, communications presented in congresses and other types of documents are excluded from this study. In this respect, Law et al. (2009) argue that conference proceedings, books and professional journals use a peer-review system different from those used in scientific journals, wherein multiple rounds of reviews follow one another before an article is accepted for publication.

First, we set a time horizon that would determine our search in the two main worldwide suppliers of scientific literature (Web of Science and Scopus). The year 1983 was established as a starting point, and the search was continued until 2015, the last full year before the period in which this research began to take shape (March-July 2016), to include finished years in our analysis.

Justification as to why 1983 was taken as year one involves taking into account the close link that mobile technology has with the smartphone concept, and the fact that it was in 1983 when Apple, in collaboration with the design company Frog Design, first created a landline with a touch screen interface that allowed various digital functionalities, such as saving contact information (Pastor, 2014).

Our search focused on the principal databases of bibliographic references and citations of periodical publications, such as articles from scientific journals, books and other types of printed material. These databases are the Web of Science, owned by Thomson Reuters, and Scopus, owned by Elsevier (Ministerio de Economía y Competitividad, 2015).

The search process took place over a period of four months (from 16 March, 2016 to 16 July, 2016), with the results for the analysis and selection of articles renewed monthly. The procedure used in the search for articles in the databases is presented below:

In both databases, the search was performed in an advanced manner using the following criteria:

- It was decided to search by means of keywords or topics (KEY) (TS) and in two groups of words (OR) combined in a mandatory way (AND). On the other hand, the decision regarding the final search terms was based on the objective of our study, the review of other scientific articles on tourism and new technologies, as well as the recommendations of experts in librarianship and documentation. In this way, the result of the search formula for Web of Science in the first place, and later that for Scopus, was the following:

TS $=$ (mobile OR smartphone OR app OR application) AND TS $=$ (touris* OR hospitality OR hotel OR travel)

KEY (mobile OR smartphone OR app OR application) AND KEY (touris* OR hospitality OR hotel OR travel)

- The search was carried out in all languages and in terms of articles.

- The time period was from 1983 to 2015 inclusive.

- The fourth and final step for Scopus was to select the type of document, which, as previously explained, consisted of scientific articles. 
- In the "more adjustments" section, inside the "main collection of the Web of Science: Index of citations", the indices most closely related to our area of knowledge were marked, that is, the "Science Citation Index Expanded" and the "Social Sciences Citation Index".

- Finally, the search was refined for the category "Hospitality, Leisure, Sport and Tourism" within the different categories offered by the Web of Science.

With these criteria, 519 papers were obtained in the Web of Science and 923 articles in Scopus.

Once the results were obtained in the respective databases, it was necessary to be able to work with them. In this respect, we had to extract the relevant data and dump it in a bibliographic reference manager, for which we chose Mendeley. For such a task, it was therefore necessary to obtain the data in a format compatible with the bibliographic manager in such a way that the 519 records of the Web of Science database aws exported in BibTex format, while the 923 records of Scopus were made in the Ris format. The last step to enable each article to be handled involved importing the data to Mendeley.

The analysis and selection of articles was performed independently with respect to the database, and it was only after having obtained the articles that were going to be the result of the bibliographic review that the elimination of duplicates would be applied (after a first test for the elimination of duplicates, it was found that these numbered fewer than twenty). In this way, several phases in the selection of articles can be distinguished, in which at all times the three authors of the investigation were involved:

- Phase 1: Selection of articles based on the title, summary and keywords. After a first reading of the aforementioned criteria, it was decided whether to keep the article for further analysis by tagging the paper with a star in Mendeley for its maintenance, or with a point when any doubt was generated.

- Phase 2: Search of the full articles that have been selected. The search was made through the electronic resources of the library of the University of Seville, as well as through Google for those that were not present on the University website.

- Phase 3: Once we had the vast majority of the full articles, the final selection was carried out in which a more in-depth reading of those articles that merited some kind of doubt for their consideration in the analysis. Finally, 49 articles were obtained by Web of Science and 146 by Scopus. At this point, all 21 duplicates were eliminated, and hence the final number of articles to analyze was 174.

- Phase 4: The tabulation of data was performed in Excel. Although the first action involved exporting the metadata from Mendeley in XML format, and then importing this data into an Excel spreadsheet, it was found that there were certain errors in the name of authors, universities, countries and keywords. This circumstance led us to the arduous task of manually entering all the data that could be analyzed (title, author, journal, year, keywords, country and university and institution or company), for which it was revised article by article.

- Phase 5: Tables and graphs were created from all the data collected, and the results of our study began to take shape. In this respect, other similar investigations studied in the second section served as a guide and pattern for the data analysis that takes place in the following section.

Regarding the variables analyzed, it must be indicated that, depending on the authors, research of a more extensive nature can be found while other studies focus on only one 
JTA

25,1

98

specific aspect. In this way, Barrios et al. (2008) analyze the impact factor of each journal, the number of citations, the collaborations between institutions, the evolution of the number of articles per year, the evolution of the number of authors per article, the number of articles per country, as well as the categorization of articles in JCR. However, other authors, such as Phillips and Moutinho (2014) and Ruhanen et al. (2015) make a more concise bibliometric study, where the study method used in each article is considered as are the main topics covered in such articles. There are even authors who focus only on analyzing the study method used in a specific area of research, such as Yoo and Bai (2013). On the other hand, we find authors, such as Keathley-Herring et al. (2016), who carry out a study to assess the maturity of a research area through a bibliometric analysis; in this case, the aspects analyzed are the publications per year, the publications in terms of study topics, the impact factor of the journals, the authors that publish the most prolifically, the countries of origin of the authors and the articles most cited.

Given this scenario, and given our spatial restrictions, research for the development of a second article that complements this first work is herein proposed. In this way, in this study, we analyze the number of articles per year, the number of articles in terms of countries and institutions, the authors of the articles and the collaborations established between countries, institutions and authors, while determining those collaborations that are carried out between universities only and those that are also carried out between universities and companies, and culminate this with the analysis of the topic dealt with in each article.

\section{Findings and data analysis}

In this section, we show the main results obtained after the tabulation of the main indicators of the selected articles. Thus, the number of articles per year, countries and universities will be analyzed. In the same way, it is interesting to highlight the number of countries and universities that participate in each article under study (these data are offered in relative terms, as, in terms of the number of articles analyzed, the analysis is more understandable based on percentage figures). On the other hand, an analysis will be carried out regarding the number of articles per author, as well as the topics dealt with in the different articles. Finally, we must point out that these results make up the first part of a more comprehensive study. Therefore, in a second publication, the methodology used in each article will be analyzed, among other variables.

\subsection{Number of articles per year}

As can be observed in Figure 1, there is an upward trend in the number of scientific productions per year with respect to mobile technology and tourism. This is a progressive trend without major lurches, except for that produced in 2014, where it jumped from 19 items to 31 . It is true, however, that of the 14 years considered, there are four years that buck this upward trend $(2003,2005,2010,2013)$. It can be observed that the default difference is anecdotal in three of these four years that break this trend, and is more significant only in 2013, with a difference of eight articles fewer.

\subsection{Number of papers per country and collaborations between countries}

This section highlights that which, in the research world, is already assumed in many scientific areas. The USA heads the list of those countries with the most articles and assumes almost 20 per cent of the total of the 174 articles studied. In second place, we find Spain and the UK, which reach almost 10 per cent each of the total number of articles. Likewise, South Korea holds third place, with 8.62 per cent of the total scientific production analyzed. These data are striking when compared with the report that Google released 


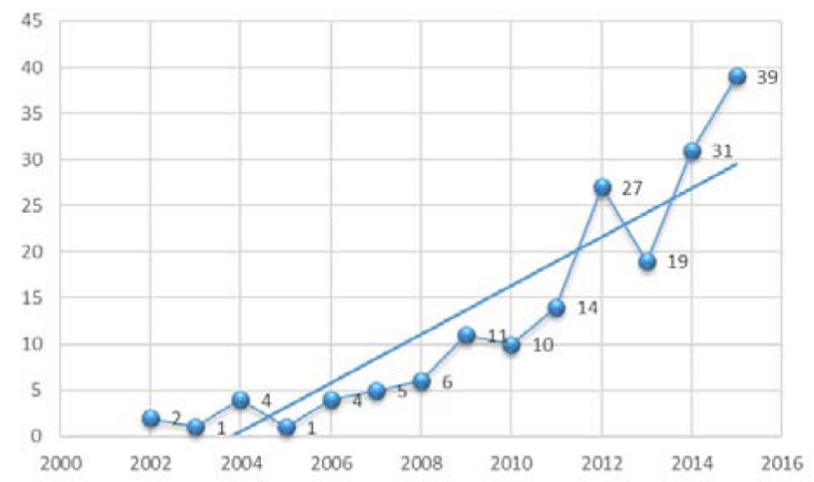

Source: Authors' own

regarding the use of smartphones (Google, 2012), which placed the USA and the UK at the forefront in the use of mobile devices, followed by Spain, France, Germany and Japan. However, in our study, Germany and Japan fail to attain very good positions, as does France, which does not even have an article, probably because in countries like Germany and France, the universities tend not to publish in academic journals.

Finally, it must be borne in mind that, in the criterion used when determining the countries according to which university, institution or company signed the article, there were articles that were subscribed by up to four countries (Table I).

In this same section, we have considered it appropriate to make a visual image of the collaboration between countries in the various papers under study. In this respect, it should be pointed out that there are 40 countries that sign the authorship of the 174 articles. In this way, and as shown in Figure 2, more than 80 per cent of the 174 articles originate in a single nation, with just over 15 per cent of the articles reaching those in which two nationalities collaborate. This figure is reduced to practically anecdotal percentages for those articles in which three or four countries collaborate (2.30 per cent and 0.57 per cent). Therefore, there is an evident lack of collaboration in scientific production in the area that we work.

\subsection{Number of papers per university; institution or company; number of universities per country and collaborations between universities, institutions or companies}

After having tabulated the different universities, institutions and companies that are behind each of the 174 articles analyzed, a total of 233 universities were obtained. Obviously, the reason why the number of universities, institutions or companies exceeds the number of articles is because more than one entity collaborates in several articles: this aspect (the collaboration) will be analyzed in the following subsection of the point that concerns us.

The universities that publish most on mobile technology and tourism include "University of the Aegean" (Greece) and "The Hong Kong Polytechnic University" with a total of six articles each, followed by "Temple University" (USA) with five, being relegated to third place (with four articles each) an Estonian University, one from the UK and one from the USA, "University of Tartu", "Bournemouth University" and "Virginia Tech". On the other hand, the universities of Spain belong to the group of those that have published three articles or fewer.

We cannot state, however, that this criterion is representative with respect to the country where the most publications have been made, as the fact that a university in a specific 
JTA

25,1

100

\begin{tabular}{|c|c|c|}
\hline No. & Countries & No. of papers \\
\hline 1 & The USA & 33 \\
\hline 2 & Spain & 17 \\
\hline 3 & The UK & 17 \\
\hline 4 & South Korea & 15 \\
\hline 5 & Taiwan & 15 \\
\hline 6 & China & 11 \\
\hline 7 & Greece & 10 \\
\hline 8 & Hong Kong & 8 \\
\hline 9 & Japan & 7 \\
\hline 10 & Germany & 6 \\
\hline 11 & Italy & 6 \\
\hline 12 & Switzerland & 5 \\
\hline 13 & Australia & 4 \\
\hline 14 & Austria & 4 \\
\hline 15 & Estonia & 4 \\
\hline 16 & Malaysia & 4 \\
\hline 17 & The Netherlands & 4 \\
\hline 18 & Denmark & 3 \\
\hline 19 & Portugal & 3 \\
\hline 20 & Thailand & 3 \\
\hline 21 & Belgium & 2 \\
\hline 22 & Canada & 2 \\
\hline 23 & Croatia & 2 \\
\hline 24 & Finland & 2 \\
\hline 25 & India & 2 \\
\hline 26 & Indonesia & 2 \\
\hline 27 & Ireland & 2 \\
\hline 28 & Israel & 2 \\
\hline 29 & Norway & 2 \\
\hline 30 & Romania & 2 \\
\hline 31 & Russia & 2 \\
\hline 32 & Singapore & 2 \\
\hline 33 & South Africa & 2 \\
\hline 34 & Others (seven more countries) & 7 \\
\hline
\end{tabular}

Figure 2.

Collaboration

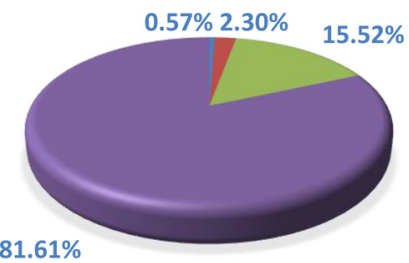

between countries

田 4 Countries $\mathbf{3}$ Countries $\mathbf{9} 2$ Countries $\mathbf{1}$ Country

Source: Authors' own 
country has published profusely does not necessarily mean that other universities in the same country have done so, albeit in smaller or greater amounts. In this respect, in Figure 3, we can distinguish the number of universities that have published in the first 32 countries of the 40 that we considered (the remaining eight coincide in the publication of a single article with a single university), whose results are very similar to those analyzed in the section where the number of articles per country was studied. The USA remains at the head of the 34 universities that have published on both mobile technology and tourism, followed by Taiwan with 21, Spain and the United Kingdom with 19 universities each and China in fourth place with 17 universities.

To clarify how the number of articles maintains a close relationship with the number of universities, in Figure 3, the number of articles published by each country is presented. It can be observed in general terms that the number of universities per country increases progressively and gradually with respect to the number of articles, which can be interpreted as because of possible collaborations between the various universities, institutions or companies of the same country in the same article, whereby the cases in which the opposite occurs (for South Korea, Hong Kong, Estonia, Malaysia, Denmark and Singapore) remains anecdotal. That is, in our research, the definition of countries is given by the universities in question, and hence if we find more universities per article than countries per article then it indicates that there are articles in which different universities in the same country collaborate with each other.

The last aspect that we consider necessary for analysis in this subsection includes the number of universities, institutions or companies that collaborate in each article. To this end, Figure 4 shows that just over half of the articles studied are presented by a single university, institution or company leaving the other half for joint collaboration. In this respect, we observe that the collaboration between two or three universities, institutions or companies monopolizes more than 40 per cent of the total number of articles, leaving less than 5 per cent for cooperation between four, five or six institutions. Thus, a balance is observed between those institutions that decide to work on their own account and those that establish ties to work jointly.

5.3.1 Collaboration among universities and between universities and companies. In this section, Figure 5 corroborates that just over half of the 174 articles under analysis are the result of the work of a single university or a single company (90 articles generated by universities and 1 by a company). Meanwhile, the remaining articles are the product of various types of collaboration, such as collaboration among two or more universities (68 articles) and university-company collaboration (15 articles). It should be noted that university-company collaboration is largely bidirectional, that is, the collaboration is between a single university with only one company. In this respect, within the 15 collaborations of this type that have been registered, there are only four articles in which several universities collaborate with a company. On the other hand, only one single article is the product of collaboration of a single university with two companies.

\subsection{Number of papers per author and collaborations between authors}

After having performed the tabulation of all the authors of the articles examined (whatever their position), 444 records were obtained. Table II shows the 51 authors who have the authorship of at least two articles. Therefore, the remaining 393 authors, who are all holders of a single article (whether shared or not with other authors), are excluded from said table.

Given the data obtained, mention must be granted to Damianos Gavalas, who is placed in first position with five articles that analyze tourism and its link with mobile technology. This author can therefore be defined as a person of bibliographic reference in this field, 
JTA

25,1

102

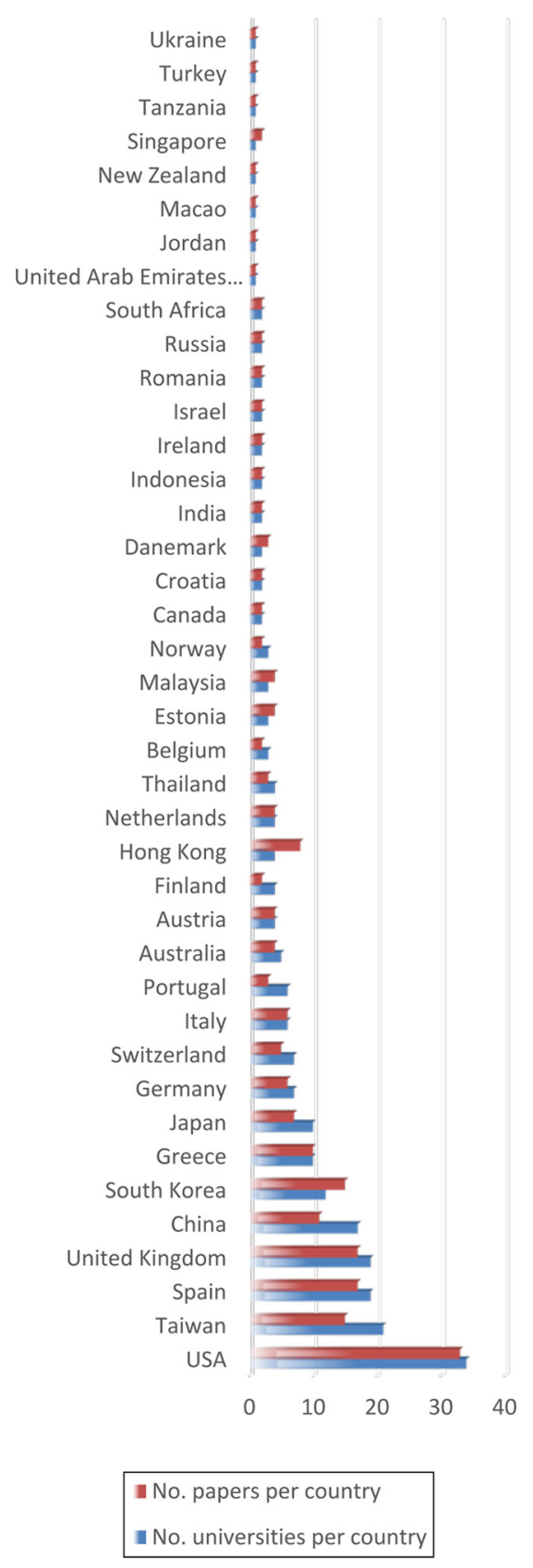

Figure 3.

Number of

universities,

institutions or

companies and

papers per country

Source: Authors' own 
along with Rein Ahas, Michael Kenteris and Dan Wang, with four articles each. In addition, there are only eight authors that have three articles each, while 39 authors possess two articles each. To conclude this recount, and with the intention of clarifying this tide of data, we compose Table III, in which these figures can be summarized.

Likewise, it is interesting to ascertain the number of authors that each article has. In this respect, the articles range from having seven authors down to one single author, as shown in Figure 6, where the percentage of the total number of articles analyzed is given. With this data, we can reveal that the most common publications involve articles of o or three authors, which cover almost 55 per cent of the total number of articles analyzed on new technologies and tourism. On the other hand, at almost 18 per cent we found the articles written by four authors, while those of a single author reach just over 14 per cent of the papers. Finally, at more than 13 per cent, we find those articles that are made by five, six, seven or eight authors.

\subsection{Topics addressed in the papers}

For the classification of the different papers that are the object of our study, a partial detailed reading of each abstract has been carried out, which led to a complete reading of the article in those cases in which any doubts arose.

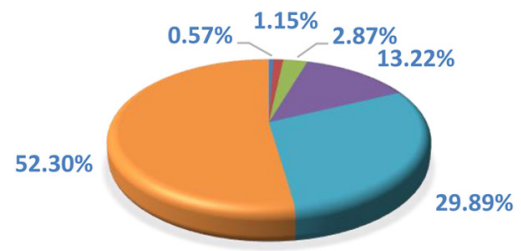

$$
\begin{array}{lll}
\mathbf{0} 6 \text { universities } & \mathbf{0} 5 \text { universities } & \mathbf{0} 4 \text { universities } \\
\mathbf{0} 3 \text { universities } & \mathbf{9} 2 \text { universities } & \mathbf{0} 1 \text { university }
\end{array}
$$

Source: Authors' own

Figure 4.

Number of universities, institutions or companies per paper

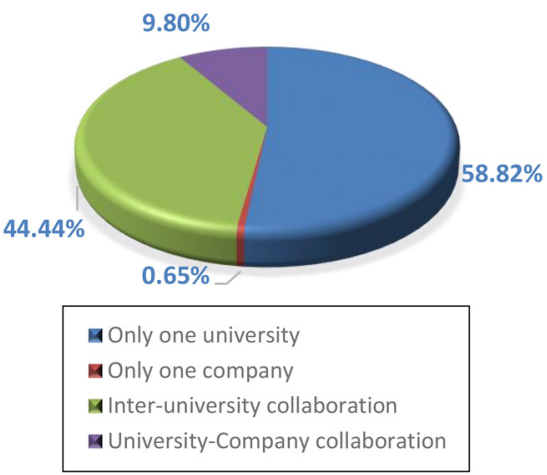

Figure 5.

Source: Authors' own 
JTA

25,1

$$
\text { N }
$$

No.

1

3

4

$\begin{array}{ll}104 & 5 \\ \end{array}$

7 8
9

10

11

12

13

14

15

16

17

18

19

20

21

22

23

24

25

26

27

28

29

30

31

32

33

34

35

36

37

38

39

40

41

42

43

44

45

46

47

48

49

50

Table II.

Number of papers per author

1
2
3
4
5
6
7

Authors

No. Papers

Gavalas, Damianos

Ahas, Rein

Kenteris, Michael

Wang, Dan

Alzua Sorzabal, Aurkene

Buhalis, Dimitrios

Chung, Namho

Fesenmaier, Daniel R.

Lamsfus, Carlos

Morosan, Cristian

Tussyadiah, Iis P.

Xiang, Zheng

Aasa, Anto

Ahmad, Kamsuriah

Alqatan, Saleh

Blum, Shane C.

Borromeo, $\mathrm{S}$.

Calabrese, Francesco

Chang, Chia-Hao

Chang, Han-Bin

Chang, Hsuan-Pu

Chu, Tzu-How

Corchado, Juan M.

Davies, Nigel

Di Lorenzo, Giusy

Dickinson, Janet E.

Economou, Daphne

Garau, Chiara

Goh, Dion Hoe-Lian

Hernández-Tamames, J. A

$\mathrm{Hu}, \mathrm{Clark}$

Hung, Jason C.

Hyun, Martin Yongho

$\mathrm{Kim}$, Jin Ki

Kuusik, Andres

Law, Rob

Leung, Rosanna

Lin, Meng-Lung

López de Ipiña, Diego

Lyu, Seong Ok

Mark, Ülar

Martín, David

No, Eunjung

Norgate, Sarah

Okazaki, Shintaro

Pan, Bing

Ratti, Carlo

Rodríguez Sánchez, M. C.

Singh, Dalbir

Speed, Chris

Tiru, Margus

Others (393 authors with one article)
Source: Authors' own 
First, according to Cheng et al. (2011), we can say that the disciplinary approaches covered by tourism research have increased over the years, resulting in the specialization of research in specific sectors. On the other hand, as stated by Cheng et al. (2011), it must be borne in mind that until 1991, tourism research journals covered a wide range of topics, while the more recently established journals handle topics of a more specialized nature. In this respect, we have taken as starting point the classification that the previous author establishes to make a first coding of the subjects that treat the articles objects of our study, as can be observed in the following table (Table IV).

Taking the above table into account, from among the 174 articles of our analysis, we have identified 14 of the 29 disciplines established by Cheng et al. (2011). In this regard, all the articles deal with technology, while tourism companies, tourist behavior and the location of businesses and tourist attractions in relation to mobile technology are topics covered in more than a third of the articles analyzed. On the other hand, issues such as market studies, the competitive environment and the administration of hotels and restaurants are barely treated in only 10 per cent of the articles; there are extremely few articles that address the management of tourism companies and the economy with respect to the adoption of mobile technology as a new sales channel.

From this first classification, and in accordance with suggestions by Oppermann and Cooper (1996), we decided to classify articles in terms of specialized topics, since the maturation of tourism research has led to a greater division of topics. This new classification process was created from the reading of the abstracts of the various articles and the analysis

\begin{tabular}{lcc}
\hline No. Papers & \% Authors & No. Authors \\
\hline Five papers & 0.23 & 1 \\
Four papers & 0.68 & 3 \\
Three papers & 1.80 & 8 \\
Two papers & 8.78 & 39 \\
One paper & 88.51 & 393 \\
Total & & 444
\end{tabular}

Source: Authors' own

Tourism and mobile devices

105

Table III.

Number of authors per number of papers

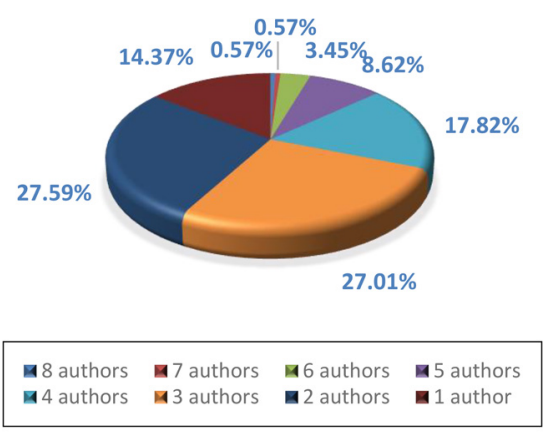

Figure 6.

Collaboration

Source: Authors' own 


\begin{tabular}{lc} 
Topics & $\%$ Papers \\
\hline Computer Science/Technology & 100 \\
Business & 43 \\
Sociology & 33 \\
Geography & 32 \\
Marketing & 12 \\
Environmental Studies & 11 \\
Hotel and Restaurant Administration & 11 \\
Urban and Regional Planning & 9 \\
Transportation & 8 \\
Cultural/Heritage Study & 6 \\
Literature & 4 \\
Gaming & 3 \\
Economics & 2 \\
Management \& Administration & 1
\end{tabular}

Topic classification of the articles according to Cheng et al. (2011)

Source: Authors' own

of the keywords therein. In this respect, 84 specific topics were identified in the 174 articles. Those topics that were covered by at least 10 per cent of the papers in question are presented below in Table $\mathrm{V}$. The geographic location linked to mobile technology is the issue of greatest concern, followed by tourist destinations, mobile applications, and all types of mobile devices. On the other hand, information services, the tourism industry in general, travel, tourist behavior and recommendation systems are included in approximately 20 per cent of the articles. Finally, issues such as the hotel business or augmented reality feature in only 10 per cent articles.

\begin{tabular}{lc}
\hline Topic & $\%$ Papers \\
\hline Location & 33 \\
Tourist Destination & 29 \\
Mobile application & 28 \\
Mobile devices & 28 \\
Information services & 25 \\
Tourism industry & 24 \\
Travel & 22 \\
Tourist behavior & 22 \\
Recommendation systems/Customization & 21 \\
Tourist guides & 16 \\
Web technology & 14 \\
Mobile technology & 14 \\
Visitor preferences & 13 \\
Social networks & 13 \\
Mobile Phone & 12 \\
Mobile Tourism Industry & 12 \\
Hospitality Businesses & 11 \\
Augmented Reality & 10 \\
Source: Authors' own &
\end{tabular}

Table V.

Topic classification of papers 


\section{Conclusions}

In this section, a summary is presented of the impressions and general tendencies observed following the review and analysis of 174 articles concerning tourism and mobile technology. The first reflection is the scarcity of scientific literature on this subject: primarily, as with respect to the 1,442 articles resulting from the first search, the selected articles only represent 12.07 per cent of the original total; and second, because in comparison with other bibliometric reviews, the number of articles selected falls below the vast majority of the bibliographic reviews analyzed, where the number of 200 articles is exceeded at all times, as in the case of Law et al. (2009) with 215 articles, Yoo et al. (2011) with 570 articles, and Zeng and Gerritsen (2014) with 279 articles. In this respect, and after sweeping through the past 32 years in the two main providers of scientific literature, we can verify that it has remained a topic of little interest, in contrast to that which is happening in twenty-first century society, in which mobile technology has become more than indispensable in the daily life of the population. Despite this, in the past four years there has been a major increase in the generation of publications that deal with the issue at hand. It is also worth noting that, although it was in 1983 when the basis of what we can now understand as mobile devices was established, it was not until 2002 that the first article dealing with this issue linked to tourism could be found.

Regarding the top ten countries that publish the most, the USA is in the lead with 33 articles, followed by Spain and the United Kingdom with 17 articles in each country. It should therefore be noted that Spain will remain in such a position in the ranking, although, on taking into account the global study conducted by Tomi Ahonen Consulting (2011), the interest in this sector is not surprising because Spain is situated with a 46 per cent penetration of smartphones after Singapore, Hong Kong, Sweden and Australia. Therefore, although smartphones constitute just one type of mobile device, they remain the most abundant, in such a way that they can help us identify trends in the sector. Of course, Asian countries are not left out of the top ten: South Korea and Taiwan have 25 papers in each country, China has 11, while Hong Kong has eight and Japan has seven. Finally, two European countries that were included in those most severely affected during the crisis are included in this list: Greece has ten articles and Italy six, which causes us to reflect on the idea of how countries that have been largely punished from the economic point of view, have generated more scientific literature on technology and tourism than others in better circumstances. In this respect, we can only remember the lapidary phrase of Albert Einstein that states that "in times of crisis, only imagination is more important than knowledge".

The dearth of collaboration between countries when publishing should be pointed out, as evidenced by the fact that almost 93 per cent of the articles are signed by a single country. Only 27 of the 174 articles contain some collaboration between two countries. We understand that in this way, despite an increasingly globalized world, knowledge remains national, without it flowing and becoming enriched through joint contributions from the global community. This shortage of international collaboration is presented as a difficult complication to understand, even more so when it is a matter as relevant as the tourism-mobile technology binomial. Collaboration between countries should contribute toward interesting and complementary solutions, as a result of the different experiences and the evolution of this binomial to the specific characteristics of each offer and demand.

On the other hand, given the comparison that is made in Section 5.2 regarding the number of articles per country that is determined herein, and the study conducted by Google on the use of smartphones on different continents (Google, 2012), it is observed that the first 
positions are held by the same countries in both cases, except for Germany, Japan and France. This comparison leads us to believe that scientific production enjoys more and greater links with the real world.

In the analysis carried out on the universities, institutions or companies that are responsible for the various studies, we observed that not only is there a huge number of these entities, but that the collaboration between them is worthy of note. Not only do we indicate which universities produce more articles, such as the University of Aegean in Greece, the Polytechnic University of Hong Kong in China and the Temple University in the USA, but also we explain in which countries the largest number of universities exist and the collaboration that takes place between universities, institutions and companies in the different articles. In this respect, we must again highlight the USA as the country in which there are a greater number of universities that write about mobile technology and tourism, followed by Taiwan, Spain, the UK and China. These results should hold no surprise, as they occur in countries where tourism is a major source of income for their economies, and it is therefore understood that university qualifications in tourism are a priority. Likewise, it is curious how the results relegate Greece to sixth place in terms of the number of universities per country, that is, although one university support the largest number of articles, the scientific production in general does not exceed ten articles in Greece. A final consideration to consider in this respect, is how slightly fewer than half of the articles analyzed establish ties between universities in different investigations, with a surprisingly high number of ties found between two or three universities, institutions or companies. Likewise, it is necessary to compare the collaboration between universities (47.70 per cent of the articles analyzed), with the collaboration between countries as shown above (7.19 per cent of the articles analyzed). Hence, our expectations are confirmed: there is collaboration between the authors of the articles, but it is largely limited to collaboration between different universities within the same country and fails to include any international collaboration.

Furthermore, the relationship between university and business is analyzed: an aspect that acquires special importance when considering mobile technology and tourism, as to some extent this relationship highlights the transfer of knowledge between the two areas of business and knowledge. In this way, we observe that only 9.80 per cent of the articles involve the aforementioned collaboration, and that the vast majority of research is carried out under the name of one single university, several universities or of universities in collaboration with any type of institution that is also dedicated to the field of research, but not with companies or institutions related to the business sector.

Focusing on the authors, the final count reached the figure of 444 different researchers. In this respect, 88.51 per cent of these authors appear in only one article, and very few are the authors of two (8.78 per cent) or more articles (2.71 per cent). Moreover, only one author, Damianos Gavalas, who is ranked first, has five articles. As in previous sections, we have studied the collaboration between authors for the production of an article and have found that 85.63 per cent of the 174 articles examined involve collaboration between two or more authors, whereby cooperation between two or three researchers supposes greater representativeness (54.60 per cent of the papers analyzed).

Finally, in relation to the content of the articles analyzed, we found the geographic location and information services to be the aspects of greatest concern, as is the adoption of mobile technology by the different agents that make up the tourism industry. The analysis of human behavior deserves special mention in both the realization of trips, and in the choice of tourist company and tourist destination, and constitutes the subject addressed in a large proportion of the research articles. It is surprising, however, how topics related to social 
networks, the administration and management of tourism companies and to augmented reality, are those that occupy the fewest articles.

In summary, this analysis reveals the role that has been played by mobile phones in tourism since the first scientific article was recorded in 2002. In this regard, in recent years, there has been a significant increase in the number of articles, finally resulting in moderate figures in relation to countries (40) and universities (233) that have formed part of the subject matter under study. In contrast to other areas of research in tourism, the relevance of this subject is therefore evident, as is the need for greater background knowledge to establish research models adapted to the new reality of tourism in a world of ever-increasing mobility.

\section{Limitations}

Through the understanding that there may be different criteria when considering one or another database with respect to the collection of articles dealing with mobile technology and tourism, we have been able to clarify that this flexibility may constitute a limitation of our study. In this respect, for example, Google Scholar is gaining more importance, and more scientific rigor is being systematized and achieved over time. However, the two databases selected guarantee the quality and quantity of articles in the best scientific journals worldwide.

The fact that only part of a bibliometric study is provided in this article must be identified as a limitation, as there are other aspects, such as the impact factor, the number of citations and the quartile within which the various journals lie, that will be studied in a second article.

A further limitation may be involved in the selection of search terms. Although we carefully studied the key words that would help us obtain all the relevant articles and not to omit any, it is possible that certain authors have not considered the same terminology as ours, even though their article is on the subject studied, with the consequent automatic elimination when performing the search in the different databases.

On the other hand, any research linked to new technologies is subject to a high and rapid degree of obsolescence, given the vertiginous rate of change to which they are exposed. Needless to say, if the "mobile" factor is added to the new technologies, then the probability of change is multiplied. Similarly, in recent years, tourism patterns have been subjected to large and expeditious changes, which have led to a new paradigm of business models in the tourism sector. Thus, in our research, two variants with a high degree of transformation are combined. Therefore, although this study focuses on a bibliometric analysis, in which the results obtained per year should not vary, this circumstance does generate a limitation for future publications, which may have a greater or lesser impact on the results obtained.

\section{Future lines of research}

This study supposes only the beginning of several lines of investigation that have yet to be explored. Therefore, once the 174 articles on mobile technology and tourism have been compiled, it is suggested that a more in-depth analysis be carried out to enable their classification in terms of tourism sub-sectors, as well as the identification of the different methodologies used in each sub-sector. In addition, it would be interesting to analyze not only the keywords proposed in the various publications but also those journals that publish the most articles. 


\section{References}

Airey, D. (1979), “Tourism education in the United Kingdom”, Tourist Review, Vol. 34 No. 2, pp. 13-15.

Barrios, M., Borrego, A., Vilaginés, A., Ollé, C. and Somoza, M. (2008), "A bibliometric study of psychological research on tourism”, Scientometrics, Vol. 77 No. 3, pp. 453-467.

Buhalis, D. and Law, R. (2008), "Progress in information technology and tourism management: 20 years on and 10 years after the internet - the state of etourism research", Tourism Management, Vol. 29 No. 4, pp. 609-623.

Burdge, R.J. (1983), "Making leisure and recreation research a scholarly topic: views of a journal editor, 1972-1982", Leisure Sciences, Vol. 6 No. 1, pp. 99-126.

Camacho-Mateos, J., Ríos Martín, M.A. and Martín-Velicia, F.A. (2015), "La borrosa línea de la web 2.0”, International Journal of World of Tourism, Vol. 2 No. 3, pp. 1-8.

Cheng, C.K., Li, X.(R.)., Petrick, J.F. and O'Leary, J.T. (2011), “An examination of tourism journal development”, Tourism Management, Vol. 32, pp. 53-61.

Connolly, D.J. and Lee, S. (2006), "Developing information technology proficiencies and fluency in hospitality students", Journal of Hospitality \& Tourism Education, Vol. 18 No. 3, pp. 15-29.

Domingo Carrillo, M.A., Chávez Miranda, M.E. and Escobar Pérez, B. (2014), "Evolución y tendencias de las publicaciones sobre revenue management en el sector turístico (1989-2013)", Papers de Turisme, Vol. 56, pp. 52-60.

Echtner, C.M. and Jamal, T.B. (1997), "The disciplinary dilemma of tourism studies", Annals of Tourism Research, Vol. 24 No. 4, pp. 868-883.

Fuchs, M., Höpken, W. and Lexhagen, M. (2014), "Big data analytics for knowledge generation in tourism destinations - a case from Sweden", Journal of Destination Marketing \& Management, Vol. 3, pp. 198-209.

Google (2012), Our Mobile Planet: Global Smartphone Users, available at: www.ladn.eu/data/document/ etude-ipsos-google_global-smartphone.pdf (accessed 18 June 2016).

Graburn, N.H.H. and Jafari, J. (1991), "Introduction: tourism social science", Annals of Tourism Research, Vol. 18 No. 1, pp. 1-11.

Grant, I. and O'Donohoe, S. (2007), "Why young consumers are not open to mobile marketing communications", International Journal of Advertising, Vol. 26 No. 2, pp. 223-246.

Ip, C., Leung, R. and Law, R. (2011), "Progress and development of information and communication technologies in hospitality", International Journal of Contemporary Hospitality Management, Vol. 23 No. 4, pp. 533-551.

Jafari, J. and Ritchie, J.R.B. (1981), "Toward a framework for tourism education problems and prospects", Annals of Tourism Research, Vol. 8 No. 1, pp. 13-34.

Jamal, T., Smith, B. and Watson, E. (2008), "Ranking, rating and scoring of tourism journals: interdisciplinary challenges and innovations", Tourism Management, Vol. 29, pp. 66-78.

Keathley-Herring, H., Van Aken, E., Gonzalez-Aleu, F., Deschamps, F., Letens, G. and Cardenas Orlandini, P. (2016), "Assessing the maturity of a research area: bibliometric review and proposed framework”, Scientometrics, Vol. 109, pp. 927-951.

Kim, H. and Law, R. (2015), "Smartphones in tourism and hospitality marketing: a literature review", Journal of Travel \& Tourism Marketing, Vol. 32, pp. 692-711.

Korobkin, R. (1999), "Ranking journals: some thoughts on theory and methodology", Florida State University Law Review, Vol. 26, pp. 851-876.

Law, R. and Jogaratnam, G. (2005), "A study of hotel information technology applications", International Journal of Contemporary Hospitality Management, Vol. 17 No. 2, pp. 170-180.

Law, R., Chan, I. and Goh, C. (2007), "Where to find the lowest hotel room rates on the internet? The case of Hong Kong", International Journal of Contemporary Hospitality Management, Vol. 19 No. 6, pp. 495-506. 
Law, R., Leung, R. and Buhalis, D. (2009), "Information technology applications in hospitality and tourism: a review of publications from 2005-2007", Journal of Travel \& Tourism Marketing, Vol. 26 Nos 5/6, pp. 599-623.

Law, R., Leung, D., Au, N. and Lee, H.(A.) (2013), "Progress and development information technology in the hospitality industry: evidence from Cornell hospitality quarterly", Comell Hospitality Quarterly, Vol. 54 No. 1, pp. 10-24.

Leung, R. and Law, R. (2005), "An analysis of information technology publications in leading hospitality journals”, FIU Hospitality Review, Vol. 23 No. 2, pp. 55-65.

McKercher, B. (2005), “A case for ranking tourism journals", Tourism Management, Vol. 26 No. 5, pp. 649-651.

Ministerio de Economía y Competitividad (2015), available at: www.idi.mineco.gob.es/portal/site/ MICINN/menuitem.7eeac5cd345b4f34f09dfd1001432ea0/?v/gnextoid=c681ff1f422c6210VgnVCM 1000001d04140aRCRD (accessed 21 October 2015).

No, E. and Kim, J.K. (2013), "Determinants of the adoption for travel information on smartphone", International Journal of Tourism Research, Vol. 16 No. 6, pp. 534-545.

Ni, L.M., Tan, H. and Xiao, J. (2016), "Rethinking big data in a networked world", Frontiers of Computer Science, Vol. 10 No. 3, pp. 965-967.

Niininen, O., Buhalis, C. and March, R. (2007), "Customer empowerment in tourism through consumer centric marketing (CCM)", Qualitative Market Research, Vol. 10 No. 3, pp. 265-282.

Oh, H., Kim, B. and Shin, J. (2004), "Hospitality and tourism marketing: recent developments in research and future directions", International Journal of Hospitality Management, Vol. 23, pp. 425-447.

Oppermann, M. and Cooper, M. (1996), "Hospitality and tourism journals: similarities, differences and market positioning", Australian Journal of Hospitality Management, Vol. 3 No. 2, pp. 75-80.

Pastor, J. (2014), Y el primer smartphone de la historia fue..., available at: www.xatakamovil.com/ movil-y-sociedad/y-el-primer-smartphone-de-la-historia-fue (accessed 21 October 2015).

Phillips, P. and Moutinho, L. (2014), "Critical review of strategic planning research in hospitality and tourism", Annals of Tourism Research, Vol. 48, pp. 96-120.

Porter, M. (2001), "Strategy and the internet”, Harvard Business Review, Vol. 79 No. 3, pp. 63-78.

Ruhanen, L., Weiler, B., Moyle, B.D. and McLennan, C.J. (2015), "Trends and patterns in sustainable tourism research: a 25-year bibliometric analysis", Journal of Sustainable Tourism, Vol. 23 No. 4, pp. 517-535.

Sheldon, P.J. (1990), "Journals in tourism and hospitality: the perception of publishing faculty", The Journal of Tourism Studies, Vol. 1 No. 1, pp. $42-48$.

Singh, A.J. and Kasavana, M.L. (2005), "The impact of information technology on future management of lodging operations: A Delphi study to predict key technological events in 2007 and 2027", Tourism \& Hospitality Research, Vol. 6 No. 1, pp. 24-37.

Stienmetz, J.L., Levy, S.E. and Boo, S. (2013), "Factors influencing the usability of mobile destination management organization websites", Journal of Travel Research, Vol. 52 No. 4, pp. 453-464.

Tomi Ahonen Consulting (2011), Smartphone Penetration Rates by Country, available at: http:// communities-dominate.blogs.com/brands/2011/12/smartphone-penetration-rates-by-country-wehave-good-data-finally.html (accessed 20 June 2016).

Tussyadiah, I. (2013), "When cell phones become travel buddies: social attribution to mobile phones in travel", in Cantoni, L. and Xiang, Z. (Eds), Information and Communication Technologies in Tourism, Springer, Innsbruck, pp. 82-93.

van Doren, C.S., Koh, Y.K. and McCahill, A. (1994), "Tourism research: a state-of-the art citation analysis (1971-1990)", in Seaton, A.V. (Ed.), Tourism: The State of the Art, John Wiley \& Sons, Chichester, pp. 308-315. 
Weiner, G. (2001), “The academic journal: has it a future?”, Education Policy Analysis Archives, Vol. 9 No.9.

Yoo, M. and Bai, B. (2013), "Customer loyalty marketing research: a comparative approach between hospitality and business journals", International Jorunal of Hospitality Management, Vol. 33, pp. 166-177.

Yoo, M., Lee, S. and Bai, B. (2011), "Hospitality marketing research from 2000 to 2009", International Journal of Contemporary Hospitality Management, Vol. 23 No. 4, pp. 517-532.

Zeng, B. and Gerritsen, R. (2014), "What do we know about social media in tourism? A review", Tourism Management Perspectives, Vol. 10, pp. 27-36.

\section{Further reading}

ABC (2012), IBM Simon, el primer smartphone de la historia, available at: www.abc.es/20120222/ tecnologia/abci-simon-primer-smartphone-historia-201202221308.html (accessed 21 October 2015).

Elsevier (2015), available at: www.elsevier.com/about/company-information (accessed 21 October 2015).

Elsevier (2016a) available at: www.elsevier.com/solutions/scopus/content (accessed 17 June 2016).

Elsevier (2016b), Scopus has Added 5 Million pre-1996 Articles and Over 93 Million References - and We're Not Even Half-way, available at: http://blog.scopus.com/posts/scopus-has-added-5-millionpre-1996-articles-and-over-93-million-references-and-we-re-not-even (accessed 17 June 2016).

Singh, A.J., Kim, H. and Huh, C. (2006), "Differential impacts of information technology services in the Korean hotel industry: a study of management perceptions", FIU Hospitality Review, Vol. 24 No. 2, pp. 78-89.

Corresponding author

Francisco José Ortega-Fraile can be contacted at: fraortfra@alum.us.es

For instructions on how to order reprints of this article, please visit our website: 